\title{
High Risk Sexual Fantasies and Sexual Offending: An Overview of Fundamentals and Interventions
}

\author{
Astrid Rossegger ${ }^{1,2}$, Ross M. Bartels ${ }^{3}$ (D) , Jérôme Endrass ${ }^{1,2}$, Bernd Borchard ${ }^{1}$, \\ Jay P. Singh ${ }^{2,4}$ (D) \\ [1] Office of Corrections, Zurich, Switzerland. [2] Department of Psychology, University of Konstanz, Konstanz, \\ Germany. [3] School of Psychology, University of Lincoln, Lincoln, United Kingdom. [4] Publication Academy LLC, Great \\ Falls, VA, USA.
}

Sexual Offending: Theory, Research, and Prevention, 2021, Vol. 16, Article e5291, https://doi.org/10.5964/sotrap.5291

Received: 2020-11-27 • Accepted: 2021-04-28 • Published (VoR): 2021-06-15

Handling Editor: L. Maaike Helmus, Simon Fraser University, Burnaby, BC, Canada

Corresponding Author: Astrid Rossegger, Office of Corrections, Hohlstrasse 552, CH-8090 Zurich, Switzerland. Email: astrid.rossegger@ji.zh.ch

\begin{abstract}
Although deviant sexual fantasizing has been found to be an etiological factor for sexual offending, not all deviant sexual fantasies increase risk equally. The aim of the present overview is to provide readers with an introduction to key terminology, a primer on central clinical theories, and a summary of the research literature on "high risk" sexual fantasies over the past 50 years. First, the important difference between "sexual fantasy" and "sexual fantasizing" is described. Second, the link between sexual fantasizing and sexual offending is discussed, with a focus on principle moderators such as physiological reaction, personality profile, and offense-supportive beliefs. Third, the different methods used to assess sexual fantasies are discussed. Fourth, the principles and techniques behind four evidence-based approaches to treating "high risk" sexual fantasies are discussed: (1) the behavioral approach, (2) the cognitive approach, (3) the imagination approach, and (4) the mindfulness-based approach. Finally, a call is issued for practice-based quantitative and qualitative research to further explore this clinical phenomenon. The findings of such investigations would advance the field's understanding of assessment, management, and monitoring best practices for this important forensic population.
\end{abstract}

\section{Keywords}

fantasies, high risk, sexual offending, intervention, treatment, assessment 


\section{Highlights}

- There is an important difference between "sexual fantasy" and "sexual fantasizing", with the former being a knowledge structure in memory that contains information about what targets or behaviors an individual finds sexually appealing, whereas the latter is a cognitive process involving an external or internal cue activating associated sex-related information stored in one's memory.

- Not all deviant sexual fantasies are "high risk", and not all "high risk" fantasies lead to sexual offenses.

- The relationship between sexual fantasizing and sexual offending is not direct but rather moderated by three facilitatory factors: (1) physiological reaction, (2) personality profile, and (3) offense-supportive beliefs.

- Research suggest that practitioners follow one of four approaches to reduce the frequency and intensity of "high risk" sexual fantasies: (1) the behavioral approach, (2) the cognitive approach, (3) the imagination approach, and (4) the mindfulness-based approach.

The prevention of sexually motivated violence is a topic of considerable community interest internationally, as evidenced by 29 countries throughout North America, South America, Europe, Asia, Africa, and Australia having passed legislation mandating registration, community notification, and tracking for individuals convicted of sexual offenses at different risk levels (U.S. Department of Justice, 2016). In countries throughout North America, Europe, and Australia, such laws also allow for the preventative detention of individuals who are judged to be at high risk of sexual recidivism at the end of their sentence (McSherry, 2014). Although a number of structured assessment and treatment decision making tools have been developed to establish management plans for sexual recidivism risk and to aid in clinical as well as legal decision-making, such protocols do not explicitly include a potentially important and modifiable factor: "high risk" sexual fantasies (Jackson \& Hess, 2007). Hence, the aim of the present overview is to provide readers with an introduction to key terminology, a primer on key clinical theories, and a summary of the research literature on such fantasies over the past 50 years.

\section{Sexual Fantasy vs. Sexual Fantasizing}

There is an important difference between "sexual fantasy" and "sexual fantasizing". According to Bartels, Beech, and Harkins (2021), a sexual fantasy is a knowledge structure in memory, containing information about what targets or behaviors an individual finds sexually appealing (e.g., "My sexual fantasy is having sex with a woman in heeled shoes"). Sexual fantasizing, on the other hand, is a cognitive process. According to the Dual-Process Model of Sexual Thinking (DPM-ST; Bartels \& Beech, 2016; Bartels et al., 2021), an external cue (e.g., seeing a pair of heeled shoes) or an internal cue (e.g., 
a memory of a woman in heeled shoes) activates associated sex-related information stored in one's memory, giving rise to a spontaneous sexual thought. This thought will be fleeting unless it grabs the individual's attention due to eliciting a strong affective response (e.g., sexual arousal). In this instance, the sexual thought will be automatically or deliberately elaborated upon using mental imagery, typically in the form of a moving story or "script". And this elaborative process which can reflect a relived experience, a planned future experience, or a purely wished experience is what is referred to as "sexual fantasizing”. Based on this conceptual distinction, someone may have a sexual fantasy that they never fantasize about and, conversely, may fantasize about a sexual act they do not regard as a fantasy. The importance of distinguishing unintentional fleeting sexual thoughts from active sexual fantasizing will be returned to later in the discussion on assessment.

When sexual mental imagery concerns an act that is deemed culturally unacceptable (e.g., pedophilia, voyeurism, frottage, exhibitionism, fetishism, biastophilia, or sadism), it is said to be "deviant". The use of a deviant sexual fantasy is typically aligned with an existing deviant sexual interest (Noorishad, Levaque, Byers, \& Shaughnessy, 2019) and deviant sexual fantasizing has been found to be an etiological factor for sexual offending (Seto, 2019) as well as a key risk factor for sexual recidivism (Mann, Hanson, \& Thornton, 2010). However, not all deviant sexual fantasies are "high risk", and not all "high risk" fantasies lead to sexual offenses. In fact, sexual fantasies involving deviant behaviors with adults are common in the general population (Bartels \& Gannon, 2011; Joyal, Cossette, \& Lapierre, 2015), and the prevalence of child-related sexual fantasies ranges from $1.8 \%$ to $13 \%$ in men (Dombert et al., 2016; Joyal et al., 2015) and $0.4 \%$ to $7 \%$ in women (Bartova et al., 2021; Tozdan et al., 2020). The question raised, then, is what distinguishes "high risk" sexual fantasies that might lead to actual offenses from those that are a part of "normal" human experience?

\section{The Link Between Sexual Fantasizing and Sexual Offending}

Research indicates that fantasizing about a deviant sexual act is often linked with engagement in the act itself by both non-offending members of the community (Klein, Schmidt, Turner, \& Briken, 2015) as well as individuals previously convicted of a sexual offense (Turner-Moore \& Waterman, 2017). However, recent studies have found that this relationship is not straightforward, with fantasy-behavior correlations observed in community samples being weaker for deviant content than for non-deviant content (Noorishad et al., 2019). Also, in a sample of only minor-attracted men, sexual fantasizing about children was not correlated with sexual offending behavior (Bailey, Bernhard, \& $\mathrm{Hsu}, 2016$ ). Such findings suggest that the relationship between sexual fantasizing and sexual offending is not direct but rather moderated by facilitatory factors. A review of 
the literature suggests three principle moderators: (1) physiological reaction, (2) personality profile, and (3) offense-supportive beliefs.

\section{Physiological Reaction}

According to Smid and Wever's (2019) Incentive Motivational Model (IMM) of sexual deviance, a competent stimulus (i.e., a stimulus with incentive value) is one that elicits a strong emotional reaction (i.e., sexual arousal). This reaction signals sexual reward and, thus, gives rise to a feeling of sexual desire; that is, an appeal towards the sexually attractive stimulus. Given its incentive value, the stimulus will be sought out for the purpose of sexual gratification (i.e., orgasm), which can include sexual fantasizing. Indeed, sexual fantasizing is often used to induce and increase sexual arousal (Gee, Ward, \& Eccleston, 2003). Thus, sexual fantasizing can contribute to one's motivation to sexually offend. And the more one fantasizes about a sexual stimulus, the higher its incentive value will become, further increasing the motivation to act.

Additional determinants of the strength of a physiological reaction to sexual fantasies include: (1) the imaginal ability of the individual, as men who can form vivid mental imagery report greater sexual arousal while sexually fantasizing (Smith \& Over, 1987); and (2) the emotional valuation of the fantasy content, whereby greater sexual arousal is elicited by positively rather than negatively appraised sexual thoughts (Little \& Byers, 2000). Hence, if an individual experiences sexual fantasies about rape - for example - as vivid, highly arousing, and positive, then they are at higher risk of engaging in such behavior. As a corollary, persons convicted of sexual offenses typically fantasize about sexual content that matches their offense, with men who have raped a woman fantasizing about rape, men who have sexually abused children fantasizing about child sexual abuse, and so forth (Gee, Devilly, \& Ward, 2004).

\section{Personality Profile}

Certain personality traits have been found to be more common in individuals who sexually fantasize about deviant content. Research on both non-offending members of the community (Baughman, Jonason, Veselka, \& Vernon, 2014) as well as persons who have been convicted of a sexual offense (Skovran, Huss, \& Scalora, 2010) has established psychopathy as one of these traits. Since low inhibition is a core aspect of psychopathy, it may be that psychopathic tendencies affect the (dis)inhibition of sexual desire and motivational goals that arise from sexual fantasizing, thus, increasing the risk of sexual offending. Towards this end, psychopathy has been found to moderate the relationship between sexual fantasizing about deviant content and engaging in such behavior in real life (Visser et al., 2015). A second personality trait that may play a moderating role is fantasy proneness, defined as a deep and profound involvement in fantasy and imagination (Rhue \& Lynn, 1987). Individuals scoring high on fantasy proneness measures have 
been found to engage in more frequent sexual fantasizing, including that which involves deviant content (Bartels, Harkins, \& Beech, 2020). However, further research is needed to determine the correlation between fantasy proneness and offending behavior.

\section{Offense-Supportive Beliefs}

Offense-supportive beliefs are a key etiological factor for sexual offending (Szumski, Bartels, Beech, \& Fisher, 2018) as well as a risk factor for sexual recidivism (Helmus, Hanson, Babchishin, \& Mann, 2013). These explicit beliefs are thought to be underpinned by implicit theories (Ward, 2000): clusters of subconscious core beliefs developed at a young age concerning oneself, others, the world, and sexuality. Implicit theories bias the processing and perception of social information in a manner that increases the risk of sexual offending (Ward, 2000) and can differ depending on the type of offense committed. For example, the implicit theories of men who have raped adult women can lead to the beliefs that women cannot be trusted, that women are sex objects, that men have a right to sex with whomever they choose, that dominance is necessary in a hostile world, and that men's sex drive is uncontrollable (Polaschek \& Gannon, 2004). In contrast, the implicit theories of men who have molested children can lead to the beliefs that children are sexual beings, that sexual abuse is harmless, that men have the right to have sex with minors, and that the adult world is hostile (Ward \& Keenan, 1999).

Implicit theories may also affect the processing of sexual fantasy content such that offense-supportive beliefs affect the fantasy-behavior link. In the DPM-ST, it is proposed that spontaneous sexual thoughts (triggered by a cue) undergo a process of appraisal. This involves validating whether the thought content is congruent with one's current beliefs. If the thought is deemed congruent, it is more likely to be elaborated upon via sexual fantasizing. For example, a man may sexually fantasize about rape if it is congruent with the belief that women are sexual objects who will enjoy sex even if it is forced upon them. Indeed, rape-supportive beliefs in community men have been found to be correlated with sexual fantasies about dominance (Bartels \& Gannon, 2009; Zurbriggen \& Yost, 2004) and rape (Greendlinger \& Byrne, 1987), and hostile beliefs about women have been found to be associated with sexually aggressive fantasies (Bartels et al., 2020).

It could be that a similar appraisal process occurs in relation to enacting offense-related behavior, in that fantasy content that is congruent with one's offense-supportive beliefs will be appraised positively and, in turn, be at a greater likelihood to be enacted. In support, sexual aggression in both men and women has been found to be associated with sexual fantasies about dominance, but only when the sexual dominance content is positively appraised (Moyano \& Sierra, 2016). Also, men convicted of rape or sexual murder have reported that the content of their offense-supportive beliefs was reflected in the content of their sexual fantasies (Beech, Fisher, \& Ward, 2005; Beech, Ward, \& Fisher, 2006) and that enacting these fantasies was the motivation for their offending. 


\section{Defining "High Risk" Sexual Fantasies}

The moderating factors discussed above are key components in the following definition of "high risk" sexual fantasies proposed by Bartels and Gannon (2011, p. 553): "mental imagery involving an elaborate sexual scenario or script with distorted aims and/or means, whose repeated use can increase the risk of the fantasizer committing a sexual offense in the presence of certain contexts and/or dispositions" (see Figure 1). This definition implies that deviant fantasy content may not increase the sexual offense risk of the fantasizer unless they possess traits that facilitate disinhibition or harbor beliefs that validate the content. Bartels and Gannon (2011) also argue that the content of "high risk" fantasies need not be deviant, necessarily, but rather can represent a distorted view of reality. For example, a man may fantasize about meeting an attractive woman in a park, leading her to his car in a display of dominance, and having intercourse with her at his apartment. In this example, there is no culturally deviant content; however, the content may be validated by the man's implicit theories (e.g., women are sex objects and there is a need to be dominant in a hostile world). This may lead the man to enact his fantasy script as intended, even if the woman does not consent, ultimately leading to the commission of a sexual offense.

\section{Figure 1}

Operational Definition of "High Risk" Sexual Fantasies (Bartels \& Gannon, 2011)

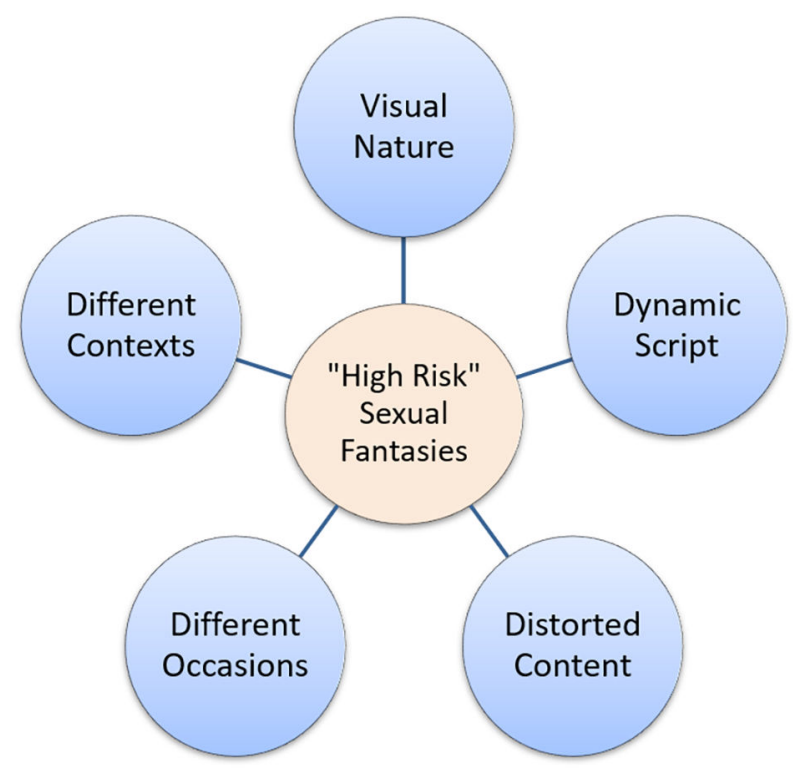




\section{Assessing "High Risk" Sexual Fantasies}

Assessing the content and use of "high risk" sexual fantasies is important for both research and clinical practice. The most common methods documented within the literature include interviews, fantasy diaries, questionnaires, and asking clients to write out a favorite sexual fantasy scenario (Leitenberg \& Henning, 1995). The first and last methods can provide richer detail about the fantasy content which is useful, since, as Turner-Moore and Waterman (2017) have noted, sexual fantasy content is often comprised of a specific target, behavior, and location (e.g., oral sex with an ex-partner on a beach). Such methods can also help uncover other useful information such as the triggers and functions of sexual fantasies. However, these two important methods have their limitations. For example, it is difficult to quantify and standardize the data obtained via interviews and narratives of fantasy scenarios, and they also do not provide a clear indication of how often clients fantasize about the content they report.

In contrast, fantasy diaries are typically completed over a prespecified time-period, and so can more readily provide frequency data as well as other useful information regarding content, triggers, and context (McKibben et al., 1994). Researchers and clinicians simply need to ensure that the necessary questions/criteria are incorporated into the response sheet of the diaries. The challenge, however, is that this method requires respondents to be aware of and honestly record this information. This can be problematic, as responses may be affected by social desirability biases, and it may be embarrassing or inconvenient to record fantasy information in real-time (e.g., when in the presence of others).

The final, and most perhaps most common, method for assessing sexual fantasies is through use of a sexual fantasy questionnaire. These questionnaires are typically comprised of a list of sexual behaviors (i.e., items) that a respondent rates on a Likert scale to capture how often they sexually fantasize about each. This enables an array of fantasy content to be assessed, including "high risk" sexual fantasies, meaning that useful information about both content and frequency can be obtained. Some notable examples of validated questionnaires include the Wilson Sex Fantasy Questionnaire (WSFQ; Wilson, 1978), the Sexual Fantasy Questionnaire (Gray et al., 2003), the Paraphilic Sexual Fantasy Questionnaire (O’Donohue et al., 1997), and the Multidimensional Assessment of Sex and Aggression (MASA; Knight et al., 1994). A number of these evidence-based instruments are used as part of routine assessment batteries in programs designed to treat sexual offending behavior (see Hudson et al., 2002). However, there are two notable challenges that researchers and clinicians should be aware of when using sexual fantasy questionnaires.

The first issue with sexual fantasy questionnaires is that the majority of sexual fantasy questionnaires do not provide a clear operational definition of "sexual fantasy", or they define the term in an all-encompassing manner (e.g., "any sexual thought that is arousing"). This is important to note when we consider the distinction between fleeting 
sexual thoughts and active sexual fantasizing. That is, a client who experiences many involuntary, fleeting sexual thoughts about children will score high on a child-related fantasy item. However, someone who frequently and deliberately envisions sexual scenarios involving children for a prolonged period of time would also score high on this item. Hence, this distinction is important to ascertain, as it can help us to better understand the nature and role of a client's sexual thoughts. And this is beneficial for case formulations, management plan development, and monitoring.

The second issue with sexual fantasy questionnaires is that they rarely provide any indication of how the items contained therein may interrelate. A client may actively fantasize about tying up an older adult, passionately kissing a young adult, and having sex with a child. These behaviors may be present within a single sexual fantasy scenario yet, because sexual fantasy questionnaires are comprised of distinct items, these fantasized behaviors will likely be treated as distinct sexual fantasies. Similarly, different behaviors may be fantasized about with different categories of people (e.g., a man with a non-exclusive interest in children may fantasize about romantic behaviors with children, but sexually aggressive behaviors with adult women). The interplay between different behaviors and targets cannot be ascertained from most questionnaires at this time, and so would require a follow-up exploration by a skilled researcher or clinician (e.g., via an interview).

\section{Treating "High Risk" Sexual Fantasies}

Given its theorized and empirical relationship with sexual offending, sexual fantasizing should be a target for treatment if the content is deemed to be "high risk" and is frequently fantasized about. It is not advised that practitioners begin focusing on the reduction of "high risk" fantasies until a therapeutic alliance has been established, as this is when clients will feel most comfortable in disclosing such personal - in some cases shameful - thoughts. When treatment does begin, it is important at the start for practitioners to emphasize that it is possible to control "high risk" fantasies, because men who sexually offend often have the implicit theory that their sexual impulses are uncontrollable (Polaschek \& Gannon, 2004). Individuals undergoing sexual offender treatment have also rated it as useful to be taught that fantasizing is not wrong in and of itself, that it is better to accept (rather than to fight) sexual thoughts, and that sexual thoughts are different from actual behavior (Dwyer \& Myers, 1990). Finally, it is recommended that a thorough diagnostic assessment be conducted at the beginning of treatment to ensure that sexual fantasies are not simply intrusive thoughts indicative of a serious mental illness such as schizophrenia, obsessive compulsive disorder, or post-traumatic stress disorder. Once these steps have been taken, research suggests that the practitioner can follow one of four approaches to reduce the frequency and intensity of "high risk" sexual 
fantasies: (1) the behavioral approach, (2) the cognitive approach, (3) the imagination approach, and (4) the mindfulness-based approach.

\section{The Behavioral Approach}

There is mixed evidence as to the usefulness of the behavioral approach in reducing the frequency and intensity of "high risk" sexual fantasies, particularly in relation to masturbatory reconditioning techniques designed to reduce the level of sexual arousal elicited by deviant sexual fantasies and/or to increase the level of arousal elicited by non-deviant fantasies. These techniques include thematic shift (Marquis, 1970), fantasy alternation (Abel, Blanchard, Barlow, \& Flanagan, 1975), directed masturbation (Maletzky, 1985), and masturbatory satiation (Marshall \& Lippens, 1977). Thematic shift involves the client masturbating while imagining acting out their deviant sexual fantasies and then switching to a non-deviant sexual fantasy prior to orgasm. Fantasy alternation involves the client masturbating on multiple occasions in a phallometric laboratory setting, alternating between deviant sexual fantasies and non-deviant sexual fantasies until the client recognizes they are able to be aroused by non-deviant stimuli.

Directed masturbation involves the practitioner instructing the client only to masturbate to non-deviant fantasies, often using prepared scripts and visual aids, to reinforce the strength of the client's arousal to this sort of fantasy, hence increasing its frequency. Masturbatory satiation involves the client masturbating while imagining acting out their deviant sexual fantasies and then, after orgasm, continuing to masturbate for an extended period of time, resulting in boredom, fatigue, and discomfort.

In a review of these techniques, Laws and Marshall (1991) concluded that directed masturbation and masturbatory satiation have empirical support for their efficacy, whereas thematic shift and fantasy alternation do not. More recently, Allen and colleagues (2020) conducted an updated systematic review and found that treatment programs that incorporated behavioral reconditioning techniques (especially those that employed more than one technique) were effective at reducing the frequency of deviant sexual fantasizing. In addition, Gannon and colleagues (2019) recently published a metaanalysis which found that the general inclusion of behavioral reconditioning techniques in sexual offending treatment programs added incrementally to the programs' efficacy in reducing sexual recidivism (Gannon, Olver, Mallion, \& James, 2019). Hence, further research is necessary to expand the evidence base to clarify how techniques following the behavioral approach can be most helpful to practitioners and their clients.

\section{The Cognitive Approach}

The cognitive approach to treatment focuses on disrupting the thought processes underlying "high risk" sexual fantasies. The most commonly employed technique by practitioners following the cognitive approach is thought suppression, which involves asking 
clients to actively try to stop imagining deviant sexual fantasies. Qualitative research suggests that men who have sexually offended also self-report engaging in thought suppression, as they view their deviant sexual fantasies as having had a causal role in their offending, or because the fantasies remind them of the consequences of their offense (Gee et al., 2004). Although thought suppression is commonsensical, the technique has been found to actually increase the frequency of targeted fantasies post-suppression, making it "at best a weak strategy, and at worst dangerous" (Shingler, 2009, p. 51).

A lesser used but empirically more promising cognitive technique involves imagery-competing tasks, which are tasks performed at the same time as the targeted mental imagery. Since both the task and the imagery compete for working memory resources, the experience of the mental imagery becomes impaired. The DPM-ST proposes that sexual fantasizing requires the resources of working memory as it involves finding, manipulating, and holding in mind the information needed to construct sexual mental imagery (Bartels et al., 2020). Based on this premise, Bartels et al. (2018) recruited a non-forensic sample to examine whether the imagery-competing task of bilateral eye-movements (performed while fantasizing sexually) led to an impairment in sexual fantasy content. As hypothesized, taxing working memory via eye-movement led to a significant reduction in sexual fantasy vividness, emotionality, and arousability, relative to the "no eye-moment" condition. This signifies a promising treatment technique that could be implemented across treatment formats (Allen et al., 2020). However, further research is needed to test its efficacy in relation to "high risk" sexual fantasies and forensic populations.

\section{The Imagination and Mindfulness-Based Approaches}

Although there is currently a limited evidence base regarding the efficacy of the imagination and mindfulness-based approaches to reducing the frequency and intensity of "high risk" sexual fantasies, there is theoretical justification for the utility of the methods falling under these modalities. In both approaches, the practitioner plays a central role, inducing deviant sexual fantasies and then helping the client to modify their reaction to the mental representation in real time. The intensity of the fantasy content can be changed depending on the practitioner's level of descriptiveness, as well as the client's moving of their eyes horizontally or vertically during the induction process (Marks, 1973).

The aim of the imagination approach is to reduce the attractiveness of "high risk" sexual fantasies for clients (Urbaniok \& Endrass, 2006). This is accomplished by methods such as pausing or modifying aspects of the sexual fantasy to dampen the client's stimulation while fantasizing. For example, practitioners can train clients to add or remove color from fantasies, or to zoom in or out of any particular aspect of their script. By reinforcing these modified fantasies, practitioners may selectively reinforce aspects of the mental representations to support the development of new, lower risk thought 
patterns. This approach shares similarities to "imagery rescripting", which has shown great promise in other clinical domains such as PTSD, social anxiety disorder, and major depression (Morina, Lancee, \& Arntz, 2017) and, thus, is worth exploring in relation to its efficacy with individuals who have sexually offended.

Mindfulness-based methods focus on helping clients experience "high risk" sexual fantasies and associated physiological reactions without engaging with, suppressing, or acting on them (Dafoe, 2011). Clients are taught how to control their attention in order to focus on the present, accepting whatever thoughts, feelings, and sensations they might be experiencing whilst fantasizing. They are not to label them as good or bad, right or wrong, legal or illegal, healthy or unhealthy, and this non-judgmental attention is held until the deviant thought is no longer present. The mindfulness-based approach is recommended for clients whose "high risk" sexual fantasies unfold unwillingly and (perceivably) uncontrollably. For such clients, mindfulness techniques may assist in reducing impulsivity, developing insight, and improving introspection (Howells, Tennant, Day, \& Elmer, 2010). Preliminary research findings on the effectiveness of such techniques are promising (Dafoe, 2011; Singh et al., 2011).

\section{Conclusion}

Due to its modifiable nature, the content of sexual fantasizing may represent an important treatment target for practitioners working with people who have sexually offended or populations vulnerable to engaging in such behavior. However, before conclusions can be made or best practice recommendations put forth, further research is necessary. Systematic review research is also needed to establish the common definitional components of "high risk" sexual fantasies across proposed models. Thereafter, qualitative investigations of practitioners who routinely work with people who have sexually offended are needed to establish the clinical utility of the identified definitional components. Of particular interest is whether practitioners believe sexual fantasies can be "high risk" in individuals not already at risk of committing a sexual offense. The findings of such quantitative and qualitative research would advance our understanding of assessment, management, and monitoring best practices for this important forensic population.

Funding: The authors have no funding to report.

Acknowledgments: The authors have no additional (i.e., non-financial) support to report.

Competing Interests: The authors have declared that no competing interests exist. 


\section{References}

Abel, G. G., Blanchard, E. B., Barlow, D. H., \& Flanagan, B. (1975, December). A controlled behavioral treatment of a sadistic rapist [Paper presentation]. Annual convention of the Association for Advancement of Behavior Therapy, San Francisco, CA, USA.

Allen, A., Katsikitis, M., Millear, P., \& McKillop, N. (2020). Psychological interventions for sexual fantasies and implications for sexual violence: A systematic review. Aggression and Violent Behavior, 55, Article 101465. https://doi.org/10.1016/j.avb.2020.101465

Bailey, J. M., Bernhard, P. A., \& Hsu, K. J. (2016). An Internet study of men sexually attracted to children: Correlates of sexual offending against children. fournal of Abnormal Psychology, 125, 989-1000. https://doi.org/10.1037/abn0000213

Bartels, R., \& Beech, A. (2016). Theories of deviant sexual fantasy. In A. Beech \& T. Ward (Eds.), The Wiley handbook on the theories, assessment and treatment of sexual offending (pp. 165-186). Wiley Blackwell.

Bartels, R. M., Beech, A. R., \& Harkins, L. (2021). Understanding sexual thoughts and sexual fantasizing: The Dual-Process Model of Sexual Thinking. In L. Craig \& R. M. Bartels (Eds.), Sexual deviance: Understanding and managing deviant sexual interests and paraphilic disorders (pp. 53-66). Wiley Blackwell.

Bartels, R. M., \& Gannon, T. A. (2009). Rape supportive cognition, sexual fantasies and implicit offense-scripts: A comparison between high and low rape prone men. Sexual Abuse in Australia and New Zealand, 2, 14-20.

Bartels, R. M., \& Gannon, T. A. (2011). Understanding the sexual fantasies of sex offenders and their correlates. Aggression and Violent Behavior, 16, 551-561. https://doi.org/10.1016/j.avb.2011.08.002

Bartels, R. M., Harkins, L., \& Beech, A. R. (2020). The influence of fantasy proneness, dissociation, and vividness of mental imagery on male's aggressive sexual fantasies. fournal of Interpersonal Violence, 35, 964-987. https://doi.org/10.1177/0886260517691523

Bartels, R. M., Harkins, L., Harrison, S. C., Beard, N., \& Beech, A. R. (2018). The effect of bilateral eye-movements versus no eye-movements on sexual fantasies. Fournal of Behavior Therapy and Experimental Psychiatry, 59, 107-114. https://doi.org/10.1016/j.jbtep.2018.01.001

Bartova, K., Androvicova, R., Krejcova, L., Weiss, P., \& Klapilova, K. (2021). The prevalence of paraphilic interests in the Czech population: Preference, arousal, the use of pornography, fantasy, and behavior. fournal of Sex Research, 58, 86-96. https://doi.org/10.1080/00224499.2019.1707468

Baughman, H. M., Jonason, P. K., Veselka, L., \& Vernon, P. A. (2014). Four shades of sexual fantasies linked to the Dark Triad. Personality and Individual Differences, 67, 47-51. https://doi.org/10.1016/j.paid.2014.01.034

Beech, A., Fisher, D., \& Ward, T. (2005). Sexual murderers' implicit theories. fournal of Interpersonal Violence, 20, 1366-1389. https://doi.org/10.1177/0886260505278712

Beech, A. R., Ward, T., \& Fisher, D. (2006). The identification of sexual and violent motivations in men who assault women: Implication for treatment. Journal of Interpersonal Violence, 21, 1635-1653. https://doi.org/10.1177/0886260506294242 
Dafoe, T. (2011). Mindfulness meditation: A new approach to working with sexual offenders [Master's thesis, University of Toronto]. University of Toronto TSpace Repository. http://hdl.handle.net/1807/27315

Dombert, B., Schmidt, A. F., Banse, R., Briken, P., Hoyer, J., Neutze, J., \& Osterheider, M. (2016). How common is men's self-reported sexual interest in prepubescent children? fournal of Sex Research, 53, 214-223. https://doi.org/10.1080/00224499.2015.1020108

Dwyer, S. M., \& Myers, S. (1990). Sex offender treatment: A six-month to ten-year follow-up study. Annals of Sex Research, 3, 305-318. https://doi.org/10.1177/107906329000300303

Gannon, T. A., Olver, M. E., Mallion, J. S., \& James, M. (2019). Does specialized psychological treatment for offending reduce recidivism? A meta-analysis examining staff and program variables as predictors of treatment effectiveness. Clinical Psychology Review, 73, Article 101752. https://doi.org/10.1016/j.cpr.2019.101752

Gee, D. G., Devilly, G. J., \& Ward, T. (2004). The content of sexual fantasies for sexual offenders. Sexual Abuse, 16, 315-331. https://doi.org/10.1177/107906320401600405

Gee, D., Ward, T., \& Eccleston, L. (2003). The function of sexual fantasies for sexual offenders: A preliminary model. Behaviour Change, 20, 44-60. https://doi.org/10.1375/bech.20.1.44.24846

Gray, N. S., Watt, A., Hassan, S., \& MacCulloch, M. J. (2003). Behavioral indicators of sadistic sexual murder predict the presence of sadistic sexual fantasy in a normative sample. Fournal of Interpersonal Violence, 18, 1018-1034. https://doi.org/10.1177/0886260503254462

Greendlinger, V., \& Byrne, D. (1987). Coercive sexual fantasies of college men as predictors of selfreported likelihood to rape and overt sexual aggression. fournal of Sex Research, 23, 1-11. https://doi.org/10.1080/00224498709551337

Helmus, L., Hanson, R. K., Babchishin, K. M., \& Mann, R. E. (2013). Attitudes supportive of sexual offending predict recidivism: A meta-analysis. Trauma, Violence \& Abuse, 14, 34-53. https://doi.org/10.1177/1524838012462244

Howells, K., Tennant, A., Day, A., \& Elmer, R. (2010). Mindfulness in forensic mental health: Does it have a role? Mindfulness, 1, 4-9. https://doi.org/10.1007/s12671-009-0001-x

Hudson, S. M., Wales, D. S., Bakker, L., \& Ward, T. (2002). Dynamic risk factors: The Kia Marama evaluation. Sexual Abuse, 14, 103-119. https://doi.org/10.1177/107906320201400203

Jackson, R. L., \& Hess, D. T. (2007). Evaluation for civil commitment of sex offenders: A survey of experts. Sexual Abuse, 19, 425-448. https://doi.org/10.1177/107906320701900407

Joyal, C. C., Cossette, A., \& Lapierre, V. (2015). What exactly is an unusual sexual fantasy? fournal of Sexual Medicine, 12, 328-340. https://doi.org/10.1111/jsm.12734

Klein, V., Schmidt, A. F., Turner, D., \& Briken, P. (2015). Are sex drive and hypersexuality associated with pedophilic interest and child sexual abuse in a male community sample? PLoS One, 10, Article e0129730. https://doi.org/10.1371/journal.pone.0129730

Knight, R. A., Prentky, R. A., \& Cerce, D. D. (1994). The development, reliability, and validity of an inventory for the Multidimensional Assessment of Sex and Aggression. Criminal fustice and Behavior, 21, 72-94. https://doi.org/10.1177/0093854894021001006 
Laws, D. R., \& Marshall, W. L. (1991). Masturbatory reconditioning with sexual deviates: An evaluative review. Advances in Behaviour Research and Therapy, 13, 13-25. https://doi.org/10.1016/0146-6402(91)90012-Y

Leitenberg, H., \& Henning, K. (1995). Sexual fantasy. Psychological Bulletin, 117, 469-496. https://doi.org/10.1037/0033-2909.117.3.469

Little, C. A., \& Byers, E. S. (2000). Differences between positive and negative sexual cognitions. The Canadian fournal of Human Sexuality, 9, 167-179.

Maletzky, B. M. (1985). Orgasmic reconditioning. In A. Bellack \& M. Hersen (Eds.), Dictionary of behaviour therapy techniques (pp. 157-158). Pergamon.

Mann, R. E., Hanson, R. K., \& Thornton, D. (2010). Assessing risk for sexual recidivism: Some proposals on the nature of psychologically meaningful risk factors. Sexual Abuse, 22, 191-217. https://doi.org/10.1177/1079063210366039

Marks, D. F. (1973). Visual imagery differences and eye movements in the recall of pictures. Perception \& Psychophysics, 14, 407-412. https://doi.org/10.3758/BF03211175

Marquis, J. N. (1970). Orgasmic reconditioning: Changing sexual object choice through controlling masturbation fantasies. Fournal of Behavior Therapy and Experimental Psychiatry, 1, 263-271. https://doi.org/10.1016/0005-7916(70)90050-9

Marshall, W. L., \& Lippens, K. (1977). The clinical value of boredom: A procedure for reducing inappropriate sexual interests. The fournal of Nervous and Mental Disease, 165, 283-287. https://doi.org/10.1097/00005053-197710000-00009

McKibben, A., Proulx, J., \& Lusignan, R. (1994). Relationships between conflict, affect and deviant sexual behaviors in rapists and paedophiles. Behaviour Research and Therapy, 32, 571-575. https://doi.org/10.1016/0005-7967(94)90147-3

McSherry, B. (2014). Managing fear: The law and ethics of preventative detention and risk assessment. Routledge.

Morina, N., Lancee, J., \& Arntz, A. (2017). Imagery rescripting as a clinical intervention for aversive memories: A meta-analysis. fournal of Behavior Therapy and Experimental Psychiatry, 55, 6-15. https://doi.org/10.1016/j.jbtep.2016.11.003

Moyano, N., \& Sierra, J. C. (2016). Sexual victimisation, sexual cognitions, desire and excitation/ inhibition in community Spanish male and female sexual aggressors. fournal of Sexual Aggression, 22, 36-51. https://doi.org/10.1080/13552600.2014.996614

Noorishad, P. G., Levaque, E., Byers, E. S., \& Shaughnessy, K. (2019). More than one flavour: University students' specific sexual fantasies, interests, and experiences. The Canadian fournal of Human Sexuality, 28, 143-158. https://doi.org/10.3138/cjhs.2019-0024

O’Donohue, W., Letourneau, E. J., \& Dowling, H. (1997). Development and preliminary validation of a paraphilic sexual fantasy questionnaire. Sexual Abuse, 9, 167-178. https://doi.org/10.1177/107906329700900302

Polaschek, D. L., \& Gannon, T. A. (2004). The implicit theories of rapists: What convicted offenders tell us. Sexual Abuse, 16, 299-314. https://doi.org/10.1177/107906320401600404 
Rhue, J. W., \& Lynn, S. J. (1987). Fantasy proneness and psychopathology. fournal of Personality and Social Psychology, 53, 327-336. https://doi.org/10.1037/0022-3514.53.2.327

Seto, M. C. (2019). The motivation-facilitation model of sexual offending. Sexual Abuse, 31, 3-24. https://doi.org/10.1177/1079063217720919

Shingler, J. (2009). Managing intrusive risky thoughts: What works? fournal of Sexual Aggression, 15, 39-53. https://doi.org/10.1080/13552600802542011

Singh, N. N., Lancioni, G. E., Winton, A. S., Singh, A. N., Adkins, A. D., \& Singh, J. (2011). Can adult offenders with intellectual disabilities use mindfulness-based procedures to control their deviant sexual arousal? Psychology, Crime \& Law, 17, 165-179.

https://doi.org/10.1080/10683160903392731

Skovran, L. C., Huss, M. T., \& Scalora, M. J. (2010). Sexual fantasies and sensation seeking among psychopathic sexual offenders. Psychology, Crime \& Law, 16, 617-629. https://doi.org/10.1080/10683160902998025

Smid, W. J., \& Wever, E. C. (2019). Mixed emotions: An incentive motivational model of sexual deviance. Sexual Abuse, 31, 731-764. https://doi.org/10.1177/1079063218775972

Smith, D., \& Over, R. (1987). Correlates of fantasy-induced and film-induced male sexual arousal. Archives of Sexual Behavior, 16, 395-409. https://doi.org/10.1007/BF01541422

Szumski, F., Bartels, R. M., Beech, A. R., \& Fisher, D. (2018). Distorted cognition related to male sexual offending: The multi-mechanism theory of cognitive distortions (MMT-CD). Aggression and Violent Behavior, 39, 139-151. https://doi.org/10.1016/j.avb.2018.02.001

Tozdan, S., Dekker, A., Neutze, J., Santtila, P., \& Briken, P. (2020). Sexual interest in children among women in two nonclinical and nonrepresentative online samples. Sexual Medicine, 8, 251-264. https://doi.org/10.1016/j.esxm.2020.01.007

Turner-Moore, T., \& Waterman, M. (2017). Men presenting with sexual thoughts of children or coercion: Flights of fancy or plans for crime? Journal of Sexual Medicine, 14, 113-124. https://doi.org/10.1016/j.jsxm.2016.11.003

Urbaniok, F., \& Endrass, J. (2006). Therapeutic work with offense-related fantasies. Swiss Archives of Neurology and Psychiatry, 157, 15-22.

U.S. Department of Justice. (2016). SMART summary: Global survey of sex offender registration and notification systems.

https://smart.ojp.gov/sites/g/files/xyckuh231/files/media/document/global-survey-2016final.pdf

Visser, B. A., DeBow, V., Pozzebon, J. A., Bogaert, A. F., \& Book, A. (2015). Psychopathic sexuality: The thin line between fantasy and reality. fournal of Personality, 83, 376-388. https://doi.org/10.1111/jopy.12110

Ward, T. (2000). Sexual offenders' cognitive distortions as implicit theories. Aggression and Violent Behavior, 5, 491-507. https://doi.org/10.1016/S1359-1789(98)00036-6

Ward, T., \& Keenan, T. (1999). Child molesters' implicit theories. fournal of Interpersonal Violence, 14, 821-838. https://doi.org/10.1177/088626099014008003

Wilson, G. (1978). The secrets of sexual fantasy. J. M. Dent \& Sons. 
Zurbriggen, E. L., \& Yost, M. R. (2004). Power, desire, and pleasure in sexual fantasies. fournal of Sex Research, 41, 288-300. https://doi.org/10.1080/00224490409552236

IATSO=-

International Association for the
Ireatment of Sexucl Offenders

Sexual Offending: Theory, Research, and Prevention (SOTRAP) is the official journal of the International Association for the Treatment of Sexual Offenders (IATSO).
(P) leibniz-psychology.org

PsychOpen GOLD is a publishing service by Leibniz Institute for Psychology (ZPID), Germany. 